\title{
Melanoma maligno cutâneo: sistema de pontos (scoring system) para auxílio no diagnóstico histopatológico
}

\section{Cutaneous malignant melanoma: scoring system to assist in the histopathologic diagnosis}

Luiz Alberto Veronese'; José Eduardo Corrente²; Mariangela Esther Alencar Marques ${ }^{3}$

\section{unitermos resumo}

Melanoma

Introdução: O diagnóstico histopatológico de algumas lesões melanocíticas pode ser muito difícil, mes-

Sistema de score

mo para especialistas, mas há casos em que a dificuldade surge pela inadequada e subjetiva aplicação

Diagnóstico diferencial

dos critérios diagnósticos. Objetivo: O objetivo deste estudo é desenvolver um método de aplicação

Nevo de Spitz

sistemática desses critérios, atribuindo valores para os mais importantes. Material e métodos: Selecionaram-se os critérios mais relevantes para o diagnóstico de melanoma, atribuindo valores de 1 a 5 de acordo com sua importância. Foram escolhidos 101 casos de melanomas de tipo extensivo-superficial com menos de $2 \mathrm{~mm}$ de espessura para análise comparativa com 33 lesões melanocíticas benignas (13 nevos de Spitz, seis de Reed, seis displásicos, três congênitos, três adquiridos, um combinado e um recorrente). Resultados: A soma dos valores dados aos critérios (score) apresentou diferença significativa entre lesões malignas e benignas, mostrando que esse método pode ser útil ao patologista cirúrgico generalista em sua rotina diária. Conclusão: A aplicação objetiva e sistemática dos critérios histopatológicos pelo sistema de pontos (scoring system) pode ajudar o diagnóstico diferencial entre maligno e benigno em muitas lesões, porém não tendo o efeito desejado nas lesões melanocíticas de comportamento biológico indeterminado.
\end{abstract}

abstract

Introduction: The histopathological diagnosis of melanocytic lesions may be very difficult, even by experts within the field. The challenge can come from inaccurate and/or subjective application of the diagnosis criteria. Aim: The goal of this study was to develop a method of systematic application of histopathological criteria as a result of the most relevant microscopic characteristics. Material and methods: The most important criteria to diagnosing melanoma on histopathological bases were selected and given points ranging from 1 to 5 according to their relevance to the melanoma diagnosis. A total of 101 cases of extensive-superficial melanoma less than $2 \mathrm{~mm}$ thick were comparatively analysed with 33 benign melanocytic lesions (thirteen Spitz nevi, six Reed nevi, six dysplastic nevi, three congenital nevi, three acquired nevi, one combined nevus and one recurrent nevus). Results: The total amount of values obtained on histopathological criteria (scores) pointed out significant statistical differences between benign and malignant lesions, what makes this method useful for surgical pathologist in daily routines. Conclusion: The objective and systematic application of histopathological criteria by means of the scoring system may be helpful in the differential diagnosis between benign and malignant melanocytic neoplasms, but the approach was not able to distinguish melanocytic lesions of unknown biological behavior.

\section{key words} Melanoma

Scoring system

Differential diagnosis

Spitz nevus

\footnotetext{
1. Médico patologista do Instituto de Patologia de Araçatuba (SP); doutor em Patologia pela Faculdade de Medicina de Botucatu, da Universidade Estadual Paulista (FMB/UNESP); professor consultor do Departamento de Patologia da FMB/UNESP.

2. Professor-adjunto do Departamento de Bioestatística do Instituto de Biociências de Botucatu (BB/UNESP).

3. Professora-assistente doutora do Departamento de Patologia da FMB/UNESP.

Trabalho realizado no Departamento de Patologia da FMB/UNESP, fazendo parte da tese de doutorado do autor, defendida em 2/12/2004 com o título Melanoma maligno cutâneo: sistema de pontos (scoring system) para auxilio no diagnóstico histopatológico. Sem auxilio de agência de fomento.

Os resultados preliminares deste trabalho foram apresentados sob forma de pôster no II Congresso Intercontinental de Patologia, realizado em Foz do Iguaçu-PR, em junho/2004, e também no 59
} Congresso Brasileiro de Dermatologia, realizado em Natal-RN, em setembro de 2004, na forma de apresentação oral. 


\section{Introdução}

A incidência do melanoma maligno cutâneo tem aumentado no mundo. Nos Estados Unidos, passou de 1:1.500 pessoas em 1953 para 1:100 pessoas em $1996^{(32)}$. Apesar dos esforços da mídia em divulgar programas de detecção precoce dessa doença, em algumas regiões do mundo o número de melanomas invasivos não diminuiu, aumentando os casos de melanoma in situ e finos de bom prognóstico ${ }^{(4)}$.

Devido às campanhas realizadas e ao conseqüente esclarecimento da população, lesões cada vez mais precoces começaram a ser examinadas pelos clínicos e patologistas. Como várias dessas lesões ainda não atingiram seu desenvolvimento pleno, sua imaturidade e, conseqüentemente, seu aspecto morfológico incomum podem causar dificuldades no diagnóstico definitivo.

Outro grande problema na patologia das lesões melanocíticas é a existência de uma série de entidades benignas que podem simular melanoma, podendo ser citados como exem-

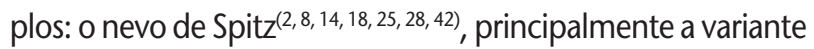
juncional e pagetóide ${ }^{(7)}$; o nevo de halo ${ }^{(16,20)}$; o nevo congênito em crianças $^{(13)}$; o pseudomelanoma ou nevo recorrente ${ }^{(19,22)}$ e o nevo de células fusiformes pigmentado(31). Entre os diagnósticos mais difíceis estão as chamadas lesões spitzóides, que sem dúvida compõem um dos maiores desafios diagnósticos da patologia cirúrgica. Vários estudos $(5,11,12,19,23,24,27,29,34,41)$ descrevem com detalhes as dificuldades diagnósticas dessas lesões e propõem algumas opções para um diagnóstico mais seguro, mas todos são unânimes em afirmar que nem sempre é possível um diagnóstico confiável entre maligno e benigno nesses casos. Alguns nevos de sítios específicos também são propensos a apresentar aspecto atípico, como o nevo acral e o nevo genital ${ }^{(15)}$.

Considerando os motivos anteriormente relatados, o diagnóstico de melanoma pode se tornar bastante problemático para os patologistas cirúrgicos. Clinicamente, a dificuldade é ainda maior, restando à histopatologia a total responsabilidade do diagnóstico definitivo. Diversos estudos sobre a concordância diagnóstica em lesões melanocíticas ${ }^{(6,10,17)}$, porém, não permitem acreditar que a histopatologia sempre resolva os casos acertadamente. Mesmo entre especialistas há discordância de opiniões ${ }^{(33)}$.

Um estudo clássico sobre concordância diagnóstica em

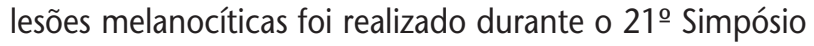
da Sociedade Internacional de Dermatopatologia, em setembro de 2000, na cidade Graz, na Áustria( ${ }^{(9)}$. Dos 67 casos estudados por seis especialistas de renome mundial, houve concordância plena somente em 33 e graus variáveis de discordância nos 34 restantes. Merece menção um dos casos em que todos concordaram que a lesão de uma criança era pseudomelanoma e, portanto, benigna: a paciente morreu de metástases de melanoma dois anos depois da remoção cirúrgica do tumor.

Farmer ${ }^{(17)}$ descreve outro estudo semelhante com a participação de dez especialistas em lesões melanocíticas, quando 37 lesões foram avaliadas e o índice de concordância plena foi de apenas 30\% (das 37 lesões, somente em 11 houve unanimidade no diagnóstico). Ackerman, que participou do evento, escreveria em 1996, em um editorial da revista Human Patholog $\gamma^{(1)}$ : "Em resumo, diagnóstico morfológico, seja em pássaros, peixes, plantas ou processos patológicos em seres humanos, é $100 \%$ subjetivo. Erros nos diagnósticos são inevitáveis; os médicos sabem disso e os pacientes deveriam ser informados desse fato. Advogados que defendem médicos e aqueles que representam os litigantes deveriam aprender a lição dos resultados daquele evento: erros não são necessariamente resultado de má prática profissional, e mesmo especialistas cometem vários deles".

Alguns autores discordaram frontalmente da declaração de Ackerman, defendendo a aplicação correta dos bem estabelecidos critérios citológicos e arquiteturais em uma suficiente amostragem das lesões, garantindo que somente uma significativa minoria das neoplasias melanocíticas ficam na zona cinzenta do diagnóstico histopatológico, onde a determinação de malignidade é bastante difícil(26).

Embora o desenvolvimento da imuno-histoquímica e da biologia molecular tenha sido espetacular nas últimas décadas, nada se conseguiu de definitivo para as lesões melanocíticas em termos de diagnóstico conclusivo e inquestionável, continuando o método da histopatologia convencional como padrão-ouro na resolução desses casos. Não existe nenhum método que permita certeza absoluta no diagnóstico de melanoma, nem no seu prognóstico. Existem numerosos casos de lesões espessas que não metastatizaram, como seria de se esperar, e de lesões finas que vieram a ser letais. Também há casos de diagnósticos benignos, feitos por especialistas, que mais tarde se revelaram incorretos. Casos como os últimos causam danos irreparáveis aos pacientes e também custam muito caro aos patologistas. Segundo Troxel ${ }^{(38,39)}$, a segunda causa mais freqüente de processos judiciais contra patologistas cirúrgicos nos Estados Unidos fica por conta das lesões melanocíticas; a primeira envolve as biópsias de lesões da mama.

A subjetividade na aplicação dos critérios sempre foi considerada a principal causa de discordância entre os 
patologistas. Outras causas, como falta de conhecimentos específicos e de experiência no assunto, também devem ser consideradas.

Os critérios microscópicos usados no diagnóstico das lesões melanocíticas são fartamente descritos na literatura, havendo o consenso de que nenhum deles é patognomônico de benignidade ou de malignidade. Existe a necessidade de sistemática avaliação do conjunto de critérios presentes em uma lesão e também de judiciosa correlação com a apresentação clínica para a emissão de diagnóstico conclusivo. Muitas vezes, apesar de todo o rigor científico empregado, não é possível uma conclusão, sendo o patologista obrigado a emitir o criticado laudo de lesão melanocítica de comportamento biológico indeterminado, o qual reflete a incompetência dos critérios aplicados em resolver aquele caso em questão e dificulta sobremaneira a aplicação correta do protocolo terapêutico.

O objetivo deste estudo é verificar se é possível criar um sistema auxiliar de diagnóstico das lesões melanocíticas através da aplicação sistemática e objetiva de critérios microscópicos já existentes para diagnóstico de melanoma. O número de critérios existentes é muito grande, por isso foi necessária uma seleção para separar aqueles considerados mais importantes (de acordo com a literatura) para confeccionar o sistema a ser proposto.

\section{Material e métodos}

Após revisão da literatura ${ }^{(40)}$, foram selecionados 19 critérios microscópicos considerados mais importantes para o diagnóstico de melanoma. Esses critérios foram colocados em seqüência ordenada para verificação de presença ou ausência nas lesões a serem estudadas. Obedecendo à relevância de cada um deles, foram atribuídos valores que variavam de 1 a 5 , ou seja, aos considerados mais relevantes para 0 diagnóstico de melanoma foi concedido o valor máximo (5); aos de menor relevância entre os selecionados foi dado o valor mínimo (1); aos critérios de importância intermediária foram atribuídos valores de 2 a 4 . Foi então construído o Quadro 1, ordenando os critérios e seus respectivos valores. Para uniformizar a aplicação dos critérios selecionados, tornase necessário que se defina cada um deles.

1. Assimetria: dividindo-se a lesão ao meio por um eixo imaginário vertical, se as duas metades forem semelhantes no seu contorno, no tamanho e na forma dos ninhos de melanócitos, na distribuição dos componentes intra-epiteliais e dérmicos e nas reações do hospedeiro, como hiperplasia epitelial e infiltrado inflamatório, deve-se chamá-la de simétrica; quando essas características não estiverem semelhantes, a lesão será assimétrica.

2. Falta de delimitação: observando-se a lesão ao microscópico, com objetiva panorâmica, se for possível afirmar exatamente onde ela começa e termina, deve-se considerá-la bem delimitada; quando não for possível determinar com exatidão seus limites, a denominação mal delimitada deve ser empregada.

3. Ninhos dérmicos maiores que os ninhos epidérmicos: o melanoma forma nódulos expansivos durante sua invasão dérmica; se esses nódulos forem de tamanho maior que os ninhos juncionais, o critério deve ser considerado presente.

4. Áreas de regressão focais: a regressão a ser considerada é aquela que não deixa dúvida, ou seja, já está na fase tardia, podendo ser completa ou incompleta. É considerada focal quando sua extensão não ultrapassa dois focos que, juntos, compreendem menos de um quarto da extensão da lesão nos cortes histológicos examinados.

5. Áreas de regressão extensas: a extensão das zonas de regressão compreende mais de um quarto da extensão da lesão nos cortes histológicos examinados.

6. Confluência de ninhos juncionais: quando três ou mais ninhos juncionais de melanócitos se fundem de maneira inequívoca, afirma-se que o critério está presente.

7. Falta de maturação: quando não há dissociação dos ninhos e diminuição do tamanho celular à medida que a lesão torna-se mais profunda na derme, considera-se ausência de maturação e assinala-se o critério como presente.

8. Borda da lesão com padrão pushing: é a forma mais freqüente de invasão dérmica pelos melanomas, com formação de nódulos ou fascículos, comprimindo as estruturas adjacentes; ao contrário, os nevos se insinuam entre as fibras colágenas com células isoladas e cordões.

9. Necrose: a necrose deve ser considerada presente quando houver grupamentos celulares mostrando processo de coagulação (necrose isquêmica); células apoptóticas não devem ser avaliadas. Para efeito de contagem no sistema de pontos, considera-se a ulceração, quando presente, como necrose, e avalia-se o critério como presente.

10. Infiltrado inflamatório leve: deve-se considerar o infiltrado inflamatório dérmico leve quando for perivascular ou liquenóide focal.

11. Infiltrado inflamatório intenso: deve-se considerar o infiltrado inflamatório intenso quando for liquenóide e se estender pela derme de maneira contínua. 


\section{Quadro 1 Critérios de avaliação de lesão melanocítica}

Exame $n^{0}$

I. Padrão geral (objetiva de pequeno aumento)

1. Assimetria

2. Falta de delimitação

3. Ninhos dérmicos maiores que os ninhos epidérmicos

4. Áreas de regressão

a. focais

b. extensas

5. Confluência dos ninhos juncionais

6. Falta de maturação

7. Borda da lesão de padrão pushing

8. Necrose

9. Infiltrado inflamatório

a. leve

b. intenso

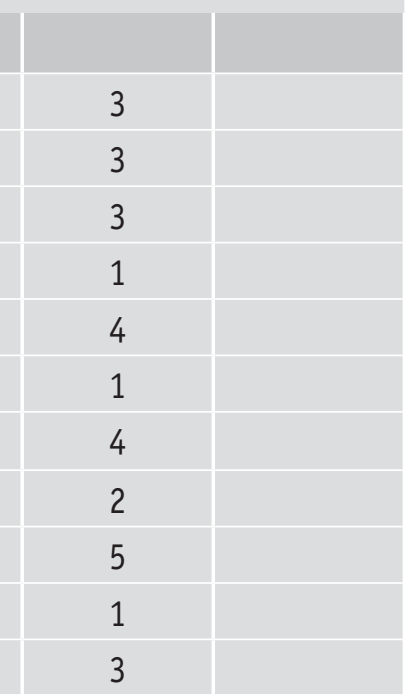

\section{Características citológicas (objetivas maiores)}

1. Melanina situada profundamente

2. Início e fim com células isoladas

3. Proliferação contígua de células isoladas

4. Melanócitos na camada granular

5. Disseminação pagetóide

a. ocasional

b. extensa

6. Núcleos grandes

7. Núcleos de forma irregular

8. Nucléolos grandes, irregulares ou múltiplos

9. Mitoses anormais

10. Mitoses

a. superficiais

b. profundas

2

1

4

4

1

5

2

2

2

5

1

5

Score
12. Melanina situada profundamente: nos melanomas invasivos (nível de Clark $\geq$ III), as células situadas profundamente no tumor podem produzir melanina; nesse caso, o critério deve ser considerado presente. Nos melanomas de nível II, as células mais profundas do tumor costumam estar no nível das extremidades das cristas interpapilares, dificultando chamá-las de profundas.

13. Início e fim com células isoladas: a presença de células melanocíticas isoladas na camada basal da epiderme na periferia de uma lesão deve ser anotada, pois, além de estar intimamente relacionada com a má delimitação, pode ser considerada também um critério para diagnóstico de melanoma, especialmente se associada à migração de melanócitos para os estratos superiores na mesma região.
14. Proliferação contígua de células isoladas: quando as células melanocíticas isoladas da camada basal se dispõem lado a lado, mesmo que focalmente, constituem um critério para diagnóstico de melanoma.

15. Melanócitos na camada granular: a presença dessas células na camada granular indica uma melanocitose pagetóide eficiente, constituindo importante critério diagnóstico.

16. Disseminação pagetóide ocasional: a migração dos melanócitos para os estratos superiores da epiderme pode ser somente focal, devendo assim ser considerada quando houver um ou dois focos da lesão onde os melanócitos suprabasalares são poucos e esparsos; esses focos estão quase sempre situados na porção central da lesão. 
17. Disseminação pagetóide extensa: quando várias regiões da lesão apresentam migração dos melanócitos, inclusive na sua periferia.

18. Núcleos grandes: considera-se grande um núcleo de melanócito quando seu volume é maior que uma vez e meia o volume do núcleo dos ceratinócitos da epiderme adjacente.

19. Núcleos de forma irregular: quando existe variação do contorno dos núcleos dos melanócitos.

20. Nucléolos grandes, irregulares ou múltiplos: o próprio nome do critério já especifica as alterações a serem procuradas nos nucléolos dos melanócitos, se presentes.

21. Mitoses anormais: a presença de mitoses de morfologia anômala de forma inequívoca (mitoses tri ou tetrapolares, por exemplo) deve ser considerada importante sinal de malignidade e, portanto, necessita ser exaustivamente procurada. Quando presente, mesmo somente uma, superficial ou profunda, deve ser anotada.

22. Mitoses superficiais: nesse item devem ser anotadas tanto as mitoses encontradas na porção dérmica superficial da lesão invasiva como aquelas vistas no componente intraepidérmico da lesão invasiva ou in situ; deve ser lembrado que o objetivo é diagnóstico, e não prognóstico.

23. Mitoses profundas: considera-se mitose profunda aquela presente em um melanoma invasivo e situada dentro de uma faixa imaginária com $0,25 \mathrm{~mm}$ de espessura medida a partir da borda profunda da lesão.

Com a finalidade de verificar a aplicabilidade do sistema, foram selecionados 147 casos de lesões melanocíticas dos arquivos do Departamento de Patologia da Faculdade de Medicina de Botucatu, da Universidade Estadual Paulista (FMB/UNESP) e de arquivos de serviços privados de patologia cirúrgica. Dessas 147 lesões, 101 eram melanomas, todos extensivo-superficiais, sendo 25 in situ (nível I de Clark) e 76 microinvasivos ou invasivos até $2 \mathrm{~mm}$ de espessura (níveis II, III e IV de Clark; não houve nenhum nível V). Esses casos foram selecionados a partir do respectivo laudo emitido e as lâminas foram posteriormente revisadas por três patologistas especialistas em lesões melanocíticas para confirmação dos diagnósticos. A exigência de os melanomas serem do tipo extensivo-superficial foi feita porque a maioria dos melanomas (cerca de 75\%) ${ }^{(13)}$ é desse tipo e, também, porque são eles que oferecem maior dificuldade diagnóstica quando ainda incipientes, principalmente pela presença de critérios que podem estar presentes em lesões benignas, como a disseminação pagetóide, por exemplo. Da mesma forma, a espessura inferior a $2 \mathrm{~mm}$ faz com que alguns critérios fiquem menos aparentes, como borda da lesão de padrão pushing, melanina situada profundamente, falta de maturação e presença de mitoses profundas. Esses casos foram submetidos a exame microscópico obedecendo à seqüência dos critérios citados na Tabela 1 e marcando os valores correspondentes a cada critério presente. No final da avaliação de cada caso os valores foram somados e o total obtido foi denominado score. Os 101 casos de melanoma estudados foram compostos por 66 pacientes do sexo feminino, 34 do masculino e um sem informações clínicas; as idades variavam entre 23 e 84 anos. Os locais mais freqüentes das lesões foram: tronco $(n=44 ; 43,6 \%)$, membros superiores $(n=23 ; 22,8 \%)$, membros inferiores $(n=14 ; 13,8 \%)$, cabeça e pescoço $(n=13 ; 12,9 \%)$, ombro ( $n=6 ; 5,9 \%)$ e um não especificado $(n=1 ; 0,9 \%)$.

Da mesma maneira, foram examinadas 33 lesões sabidamente benignas, compostas por 13 nevos de Spitz, seis de Reed, seis displásicos, três adquiridos, três congênitos, um combinado, um recorrente.

Também foram inseridos no estudo 13 casos de lesões melanocíticas consideradas de comportamento biológico indeterminado pelos especialistas consultados, ou que tiveram discordância diagnóstica entre maligno e benigno pelos mesmos patologistas.

Após a aplicação da tabela em todos esses casos, os valores obtidos (score) foram colocados em gráfico (Figura 1).

Para obter os pontos de corte no score obtido a partir da soma dos valores individuais (de cada critério), foi aplicada uma análise de agrupamentos utilizando o método de partição das k-médias aos dados individuais para as variáveis do critério de avaliação. A classificação dos grupos foi feita a partir da soma dos valores individuais. Esses grupos foram obtidos com o auxílio dos softwares S-Plus, versão $6.2^{(36)}$, e Statistica, versão $5.0^{(37)}$.

\section{Resultados}

Como já esperado, uma vez que os critérios utilizados são para diagnóstico de melanoma, as lesões benignas tiveram os menores scores (que, a partir de agora, serão chamados também de índices) e ficaram situadas à esquerda no gráfico obtido. As lesões benignas com score mais altos (acima de 10) foram: um nevo recorrente (18), um nevo de Reed (16), cinco nevos de Spitz (de 11 a 15), cinco nevos displásicos (de 11 a 15), dois nevos congênitos (12 e 13) e um nevo combinado (12). Os melanomas com invasão franca (Clark > II), ao contrário, contendo maior quantidade 


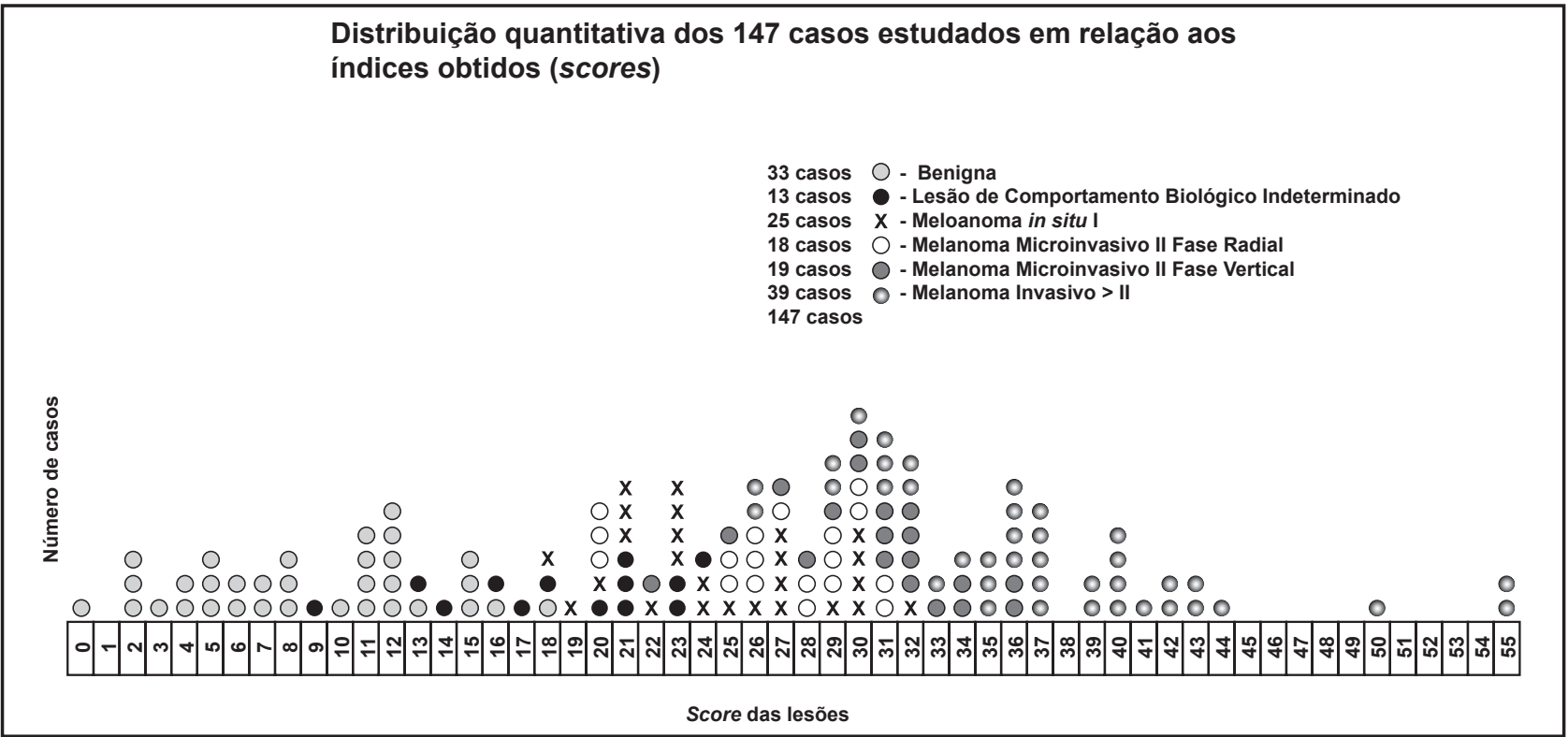

Figura 1 - Distribuição quantitativa dos 147 casos estudados em relação aos índices obtidos (score)

de critérios e, portanto, atingindo índices maiores, ficaram à direita no mesmo gráfico. Na porção central (entre 19 e 26), situaram-se os melanomas in situ, microinvasivos e também alguns invasivos. As lesões melanocíticas de comportamento biológico indeterminado posicionaram-se entre os índices maiores das lesões benignas e os índices menores das lesões malignas, sem um padrão definido. Houve somente uma coincidência, em que um melanoma in situ e uma lesão benigna (um pseudomelanoma) obtiveram o mesmo score (valor 18). Os melanomas nível II de Clark foram divididos em fase radial de crescimento (FRC) e fase vertical de crescimento (FVC), tendo sido observada uma leve tendência dos primeiros a terem índices menores que os segundos, porém sem diferença significativa (Figura 2).
Pela análise estatística utilizando o método das k-médias, foram definidos os pontos de corte. Considerando os pontos de corte, os casos foram separados em três grupos: o grupo 1 , com intervalo de 0 a 18; o grupo 2, com intervalo entre 19 e 26; e o grupo 3, com índices maiores que 26.

\section{Discussão}

Os gráficos obtidos obedeceram à expectativa dos resultados. Uma vez que o objetivo do estudo era separar as lesões melanocíticas benignas das malignas, através de uma aplicação sistemática de critérios selecionados da literatura para diagnóstico de melanoma, ordenando-os e valorizando-os quanto à sua importância, tornou-se óbvio

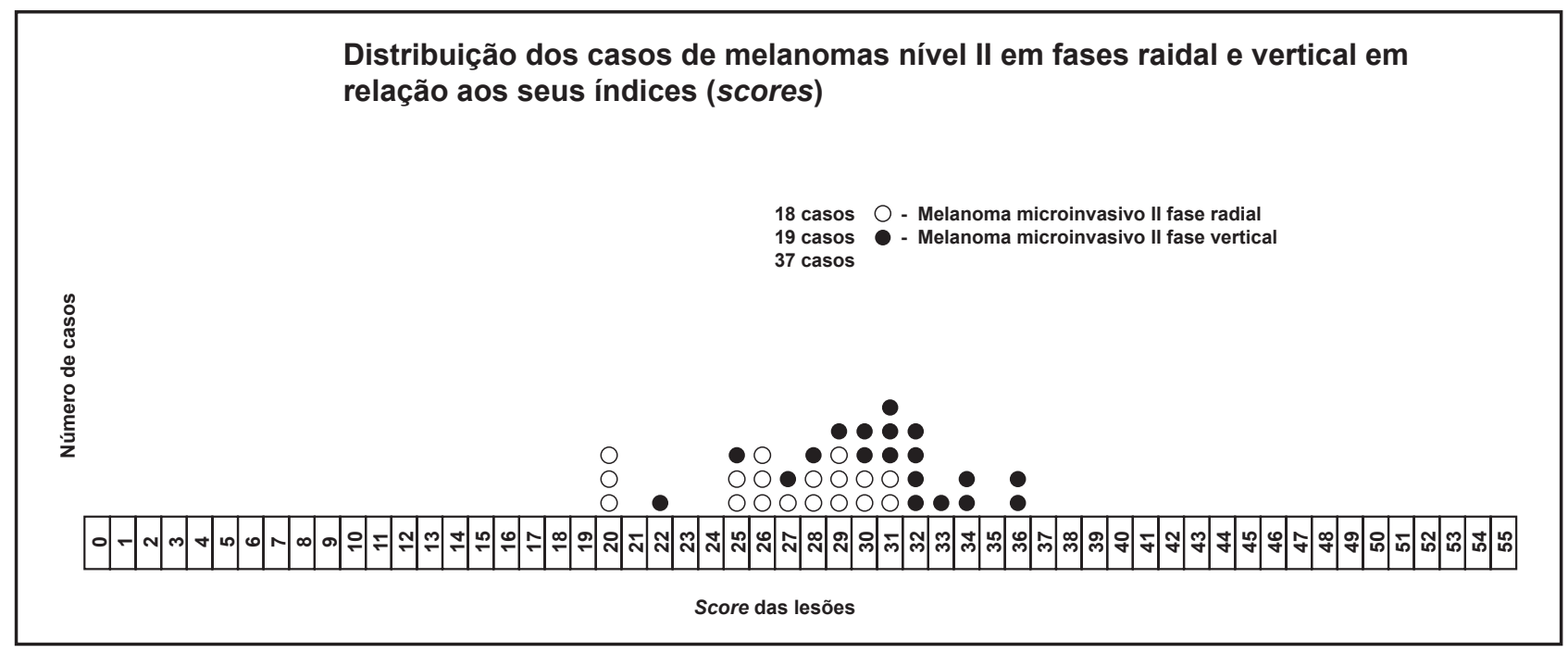

Figura 2 - Distribuição dos casos de melanomas nível Il em fases radial e vertical em relação aos seus índices (score) 
que as lesões benignas apresentaram contingente menor de critérios presentes, resultando em score mais baixo, atingindo o máximo de 18. Em contrapartida, os melanomas ficaram com índices mais elevados, iniciando em $18 \mathrm{e}$ atingindo o máximo de 55 .

Também foi observado que quanto mais se definia o melanoma como francamente invasivo (nível de Clark > II), mais à direita do gráfico a lesão se posicionava. Os melanomas nível I de Clark ocuparam uma posição intermediária, variando de 18 a 32, com uma concentração maior em torno do índice 24 (mediana), enquanto os melanomas nível II situaram-se entre 20 e 36, concentrando-se ao redor do índice 29 (mediana). Os melanomas de níveis III e IV distribuíram-se entre 26 e 55, com concentração maior no nível do índice 37 (mediana).

A análise do gráfico demonstra um escalonamento de valores à medida que a lesão deixa de ser benigna e passa a ser maligna e francamente invasiva, passando pelos estágios de melanoma in situ, microinvasivo em FRC e microinvasivo em FVC.

Apesar da sobreposição de alguns casos, essa separação parece apropriada. O maior problema estatístico reside no teste de confiabilidade do método, pois não há condições de comparação com algo de concreto e definitivo a respeito desses diagnósticos. Deve-ser lembrar que estão sendo testados diagnósticos feitos por especialistas em lâminas coradas pelo método da hematoxilina-eosina, o que não significa que estejam plenamente corretos. Não existem métodos imunohistoquímicos ou de biologia molecular que comprovem, de maneira definitiva, esses diagnósticos. Também merece menção o fato de que o método apresentado (sistema de pontos) é original, não havendo referência na literatura a estudos semelhantes que permitam uma análise comparativa. Os grupos obtidos também devem ser avaliados com alguma reserva, pois não definem diagnóstico. No grupo 1, quanto mais o score da lesão a ser analisada futuramente se aproximar do 0 , maior a sua chance de ser benigna; ao contrário, quanto mais próxima ao limite máximo do grupo 1 , que é 18 , menor a confiabilidade do método. A mesma premissa vale para o grupo 3, só que de maneira inversa, ou seja: quanto mais o score de uma lesão se afastar do valor 26 em direção a valores maiores, maior a sua probabilidade de ser maligna. O grupo 2, por sua vez, permanece como zona de dúvida entre os dois anteriormente citados, cujos valores podem não ter uma aplicabilidade maior na prática diagnóstica (estudos posteriores com número maior de casos e com seguimento clínico talvez possam auxiliar a previsão do comportamento biológico das lesões dessa faixa de score).
As lesões melanocíticas de comportamento biológico indeterminado situaram seus índices entre os valores médios das lesões benignas (mínimo de 9), estendendo-se para a zona de dúvida anteriormente relatada (grupo 2), chegando ao valor máximo de 24. Esses casos são aqueles em que os critérios realmente não possibilitam uma definição diagnóstica, ou então são lesões benignas em que alguns critérios importantes estão presentes (como a atipia celular marcada, a disseminação pagetóide e/ou a má delimitação), deixando o patologista pouco experiente temeroso em assumir a benignidade da lesão. A tentativa de obter uma resposta para esse problema pelo seguimento clínico do paciente não é satisfatória, pois a maioria dos casos é de lesões finas ou intra-epidérmicas que deverão evoluir sem conseqüências. A posição dessas lesões no gráfico obtido mostra que nenhuma delas pertence ao grupo 3, onde teriam maior probabilidade de ser malignas.

Houve um único valor de score compartilhado por um melanoma e uma lesão benigna, que foi o índice 18 . Nesse caso, a lesão benigna era um nevo recorrente que se apresentou com assimetria, falta de delimitação, início e fim com células isoladas, proliferação contígua de células isoladas na camada basal, disseminação pagetóide somente ocasional, porém com presença de melanócitos na camada granular, e com núcleos de forma irregular. A presença desses critérios justifica o nome de pseudomelanoma ${ }^{(22)}$ dado como sinônimo a esse tipo de nevo. O melanoma coincidente com o nevo recorrente era in situ (nível I de Clark) e mostrou assimetria, falta de delimitação, extensas áreas de regressão, início e fim com células isoladas, proliferação contígua de células isoladas na camada basal, disseminação pagetóide ocasional e núcleos de forma irregular. Como se pode perceber facilmente, os critérios presentes nas duas lesões são semelhantes, sendo que a história clínica, a fibrose dérmica de padrão cicatricial e a presença de restos névicos facilitam o diagnóstico de benignidade, enquanto as zonas extensas de regressão favorecem malignidade.

\section{Conclusões}

O presente estudo demonstrou que uma lesão melanocítica pode ser avaliada pelo sistema de score proposto. Sabese que ao obter a soma de valores dos critérios presentes, esse índice poderá se situar entre 0 e 18, devendo a lesão ser benigna, porém levando em conta que essa probabilidade será tanto menor quanto mais próximo o índice estiver do valor 18 . Se o score for maior que 26 , muito possivelmente a lesão será maligna, aumentando a certeza quanto mais 
se afastar desse valor para maior. A faixa de score entre 19 e 26, denominada zona cinzenta, mostra que a lesão pode ser maligna, mas ainda não oferece condições para uma avaliação segura.

O sistema de score não deve ser utilizado para obter diagnóstico preciso de uma lesão melanocítica, porém este estudo mostrou que pode ser usado como mais um método de auxílio diagnóstico nessas lesões. Assim como o estudo da proliferação celular ${ }^{(3,21,30,35)}$ pode fornecer subsídios que ajudam a situar algumas lesões dentro do espectro de benigno ou maligno, esse sistema de score também pode fazê-lo, com a vantagem de ser mais rápido e de baixo custo. Em todos esses métodos existem as chamadas zonas cinzentas, ou de sobreposição, em que não é possível definir a natureza biológica da lesão. O patologista cirúrgico generalista, na sua rotina diária, examinando doenças de muitos outros órgãos, como mama, próstata, fígado, etc., muitas vezes não tem como aprofundar seus conhecimentos em lesões melanocíticas e também não acumula experiência suficiente para definir alguns casos menos comuns. O sistema de score pode ser uma ferramenta acessível a esses profissionais, propiciando maior segurança em seus diagnósticos e lembrando que a consulta com um especialista na área sempre deve ser cogitada nos casos limítrofes e difíceis.

\section{Referências}

I. ACKERMAN, A. B. Discordance among expert pathologists in diagnosis of melanocytic neoplasms. Hum Pathol, v. I I, P. | |15-6, 1996.

2. BARNHILL, R. L. Malignant melanoma, dysplastic nevi, and Spitz tumors. Histological classification and characteristics. Clin Plast Surg, v. 27, n. 3, p. 31-60, 2000.

3. BERGMAN, R. et al. MIB-I monoclonal antibody to determine proliferative activity of Ki-67 antigen as an adjunct to the histopathologic differential diagnosis of Spitz nevi.J Am Acad Dermatol, v. 44, n. 3, p. 500-4, 2001.

4. BERWICK, M. Why are people still dying from melanoma? Arch Dermatol, v. 135, p. 1534-6, 1999.

5. BINDER, S. W. et al. The histopathology and differential diagnosis of Spitz nevus. Semin Diagn Pathol, v. I0, p. 3646, 1993.

6. BROCHEZ, L. et al. Inter-observer variation in histopathological diagnosis of clinically suspicious pigmented skin lesions. J Pathol, v. 196, p. 459-66, 2002.

7. BUSAM, K. J.; BARNHILL, R. L. Pagetoid Spitz nevus. Intraepidermal Spitz tumor with prominent pagetoid spread. Am J Surg Pathol, v. 19, n. 9, p. 1061-7, 1995.

8. CASSO, E. M.; GRING-JORGENSEN, C. M.; GRANT-KELS, J. M. Spitz nevi. J Am Acad Dermatol, v. 27, p. 901 - 13, 1992.

9. CERRONI, L:; KERL, H. Tutorial on melanocytic lesions. Am J Dermatopathol, v. 23, n. 3, p. 237-4I, 2001.

I0. COOK, M. G. Diagnostic discord with melanoma.J Pathol, v. I 82, p. 247-9, 1997

I I. CROTTY, K.A. Spitz nevus: histological features and distinction from malignant melanoma. Austral J Dermatol, v. 38, suppl. I, p. 49-53, 1997.

12. CROTTY, K. A. et al. Malignant melanoma in childhood: a clinicopathologic study of 13 cases and comparison with Spitz nevi. World J Surg, v. 16, n. 2, p. 179-85, 1992.

13. CROWSON,A. N.; MAGRO, C.M.; MIHM, M. C. The melanocytic proliferations. A comprehensive textbook of pigmented lesions. New York: Wiley-Liss, 2001.

14. ECHEVARRIA, R.; ACKERMAN, L. V. Spindle and epithelioid cell nevi in the adult - clinicopathologic report of 26 cases. Cancer, v. 20, n. 20, p. 175-89, 1967.

15. EDWARDS, S. L.; BLESSING, K. Problematic pigmented lesions: approach to diagnosis. J Clin Pathol, v. 53, n. 6, p. 409-1 8, 2000.

16. EPSTEIN, W. L. et al. Halo nevi and melanoma. JAMA, v. 225, n. 4, p. 373-7, 1973.

17. FARMER, E. R.; GONIN, R.; HANA, M. P. Discordance in the histopathologic diagnosis of melanoma and melanocytic nevi between experts. Hum Pathol, v. 27, p. 528-31, 1996.

18. GURBUZ,Y. et al.A current dilemma in histopathology: atypical Spitz tumor or spitzoid melanoma? Pediatr Dermatol, v. 19, n. 2, p. 99-102, 2002.

19. HARVELL,J.D:; BASTIAN,B.C.;LEBOIT,P.E. Persistent (recurrent) Spitz nevi. A histopathologic, immunohistochemical, and molecular pathologic study of 22 cases. Am J Surg Pathol, v. 26, n. 5, p. 654-61, 2002.

20. HARVELL, J. D.; MEEHAN, S. A.; LEBOIT, P. E. Spitz nevi with halo reaction: a histopathologic study of 17 cases. I Cutan Pathol, v. 24, n. 10, p. 61 I-9, 1997.

2।. KANTER-LEWENSOHN, L. et al. Immunohistochemical markers for distinguishing Spitz nevi from malignant melanomas. Mod Pathol, v. 10, n. 9, p. 917-20, 1997.

22. KORNBERG, R:;ACKERMAN,A. B. Pseudomelanoma: recurrent melanocytic nevus following partial surgical removal. Arch Dermatol, v. I I I, p. 1588-90, 1975.

23. MOO।, W. J. Histopathology of Spitz naevi and "Spitzoid" melanomas. Curr Top Pathol, v. 94, p. 65-77, 2001.

24. MOOI, W. J. Spitz nevus and its histologic simulators. Adv Anat Pathol, v. 9, n. 4, p. 209-21, 2002.

25. OKUM, M. R. Melanoma resembling spindle and epithelioid nevus. Arch Dermatol, v. I 15, n. 12, p. 1416-20, 1979.

26. OKUM, M. R.; KIRKHAM, N.; SLATER, D. N.What criteria reliably distinguish melanoma from benign melanocytic lesions? Histopathology, v. 37, p. 464-72, 2000.

27. ORCHARD, D. C.; DOWLING, J. P.; KELLY, J. W. Spitz nevi misdiagnosed histologically as melanoma: prevalence and clinical profile. Australas J Dermatol, v. 38, p. 12-4, 1997. 
28. PANIAGO-PEREIRA, C.; MAIZE,J.C.;ACKERMAN,A. B. Nevus of large spindle and/or epithelioid cells (Spitz nevus). Arch Dermatol, v. | |4, p. | 8| |-23, 1978.

29. PETERS, M. S.; GOELLNER, J. R. Spitz naevi and malignant melanomas of childhood and adolescence. Histopathology, v. I0, p. 1289-302, 1986.

30. RAMSAY, J. A. et al. MIB-I proliferative activity is a significant prognostic factor in primary thick cutaneous melanomas. J Invest Dermatol, v. I05, n. I, p. 22-6, 1995.

3I. REED, R. J. et al. Common and uncommon melanocytic nevi and borderline melanomas. Semin Oncol, v. 2, n. 2, p. 1 19-47, 1975.

32. RIEGEL, D. S.; FRIEDMAN, R. J.; KOPF, A. W. The incidence of malignant melanoma in the United States: issues as we approach the $21^{\text {st }}$ century. Jm Acad Dermatol, v. 34, p. 839 47, 1996.

33. SCHMOECKEL, C. How consistent are dermatopathologists in reading early malignant melanomas and lesions "precursor" to them? Am J Dermatopathol, v. 6, suppl., p. 13-24, 1984.

34. SMITH,K.J. et al. Spindle cell and epithelioid cell nevi with atypia and metastasis (malignant Spitz nevus). Am J Surg Pathol, v. 13, n. II, p. 931-9, 1989.
35. SMOLLE, J.; SOYER, H. P.; KERL, H. Proliferative activity of cutaneous melanocytic tumors defined by Ki-67 monoclonal antibody: a quantitative immunohistochemical study. Am J Dermatopathol, v. I I, p. 301-7, 1989.

36. S-PLUS 6 for Windows Guide for Statistics. vol. I and 2. Seattle, WA: Insightful Corporation. 200 I.

37. STATSOFT, INC. Statistica for Windows, vers. 5.0. Tulsa, OK. 1997.

38. TROXEL, D. B. Diagnostic errors in surgical pathology uncovered by a review of malpractice claims. Intern / Surg Pathol, v. 9, n. I, p. 6I-3, 200।.

39. TROXEL, D. B. Pitfalls in the diagnosis of malignant melanoma. Findings of a risk management panel study. Am J Surg Pathol, v. 27, p. 1278-83, 2003.

40. VERONESE, L. A.; MARQUES, M. E. A. Critérios anatomopatológicos para melanoma maligno cutâneo: análise qualitativa de sua eficácia e revisão da literatura. J Bras Patol Med Lab, v. 40, n. 2, p. 99-1 I 2, 2004.

4I. WALSH, N. et al. Spitz nevus versus spitzoid malignant melanoma: an evaluation of the current distinguishing histopatologic criteria. Human Pathology, v. 29, p. I I05- 12, 1998.

42.WEEDON, D.; LITTLE, J. H. Spindle and epithelioid cell nevi in children and adults. Cancer, v. 40, p. 217-25, 1977. 